\title{
Propriedade Intelectual para Inovação: elaboração de uma cartilha sobre inovação tecnológica para profissionais da educação
}

\author{
Intellectual Property for Innovation: preparing a spelling book about \\ technological innovation for educational professionals
}

Flaviane Mugnol do Nascimento ${ }^{1}$

Fernanda Correa de Melo ${ }^{1}$

Juliana Sartori Bonini ${ }^{1}$

Deise Mara Soares ${ }^{1}$

${ }^{1}$ Universidade Estadual do Centro-Oeste, Guarapuava, PR, Brasil

\begin{abstract}
Resumo
Ensinar conteúdos relacionados à inovação e à propriedade intelectual é essencial para preparar indivíduos críticos e atuantes na sociedade. Por isso, é importante que os profissionais da educação, responsáveis por transmitir o conhecimento, tenham embasamento e formação sobre o tema. Este artigo retrata as principais conclusões de uma pesquisa que propôs a elaboração de uma cartilha, a fim de transmitir informações sobre inovação tecnológica para profissionais da educação. Por meio de uma revisão de literatura, conteúdos acerca da temática foram reunidos, constituindo um material inovador e de fácil compreensão em formato de cartilha. Seu manuseio e acesso foi estruturado em uma linguagem que contemplasse desde profissionais da educação básica até a pós-graduação. O estudo demonstrou a necessidade de elaboração de materiais para capacitação docente no âmbito de inovação e tecnologia. Ademais, as informações da cartilha são úteis para aprimorar as ações pedagógicas e direcionar o trabalho em sala de aula.
\end{abstract}

Palavras-chave: Escola. Protobot. Renovação.

\begin{abstract}
Teaching content related to innovation and intellectual property is essential to prepare critical and active individuals in society. That is why it is important that education professionals, responsible for transmitting knowledge, have a foundation and training on the topic. This article portrays the main conclusions of an research that proposed the elaboration of a booklet in order to transmit information about technological innovation to education professionals. Through a literature review, contents about the theme were gathered, constituting an innovative and easy-tounderstand material in booklet format. Its handling and access were structured in a language that encompasses professionals from basic education to graduate school. The study demonstrated the need for materials for teacher training in the field of innovation and technology. In addition, the information in the booklet is useful for improving pedagogical actions and directing work in the classroom.
\end{abstract}

Keywords: School. Protobot. Renovation.

Área Tecnológica: Tecnologias Sociais e Educacionais. 


\section{Introdução}

O presente estudo se coloca sensível à preocupação acadêmica com a aplicação de metodologias inovadoras no ensino da inovação tecnológica e leva em conta que é de extrema importância o ensino de tecnologias atualmente, visto que o mundo vem se modificando cada vez mais num ritmo acelerado. Há 15 anos, por exemplo, não existia o Arduino (plataforma de prototipagem eletrônica de hardware livre e de placa única) que possibilita programações robóticas inimagináveis nesta época (LIBÂNEO, 2018).

Para tanto, se faz necessário saber que uma nova abordagem possibilita e requer o uso de novas práticas educacionais em sala de aula que favoreçam o aprendizado. A lógica de pensamento da atualidade requer que a educação se volte para a valorização das diferenças, da criatividade e do desenvolvimento da autonomia frente à construção do conhecimento. Nesse sentido, cabe lembrar que a tecnologia não tem mais a ver apenas com computadores, mas com a vida das pessoas, estando incluída em diversos âmbitos do cotidiano (LIBÂNEO, 2018).

A educação é um elemento transformador e, por isso, deve ser prioridade de um país. No ranking global de competitividade, o Brasil alcançou a última posição em educação, $63^{\circ}$ lugar, segundo a Revista Istoé. Se faz urgente propor alternativas para que o país tenha avanços na educação e que a formação de crianças e adolescentes seja melhorada. Tal contexto requer investimentos em formação de profissionais da educação. A produção de materiais, como cartilhas acessíveis e de fácil compreensão, vem ao encontro desse ideal (ISTOÉ, 2020).

Logo, em termos de inovação tecnológica, propriedade intelectual e transferência de tecnologia para inovação, também existe essa necessidade de atualização e adequação no meio educacional, para que a formação seja adequada às evoluções sociais (ASSUMPÇÃO et al., 2010).

Para atingir, portanto, um nível mais elevado de desenvolvimento, é preciso que se estabeleçam sistemas de inovação, com mecanismos que viabilizem políticas de ampliação evolutiva a longo prazo, almejando a transformação na base, ou seja, na educação infantil, onde se constrói o início do conhecimento, que vai gerar produções futuras, por intermédio da inovação. Agregando, assim, valor ao conhecimento, à produção e a transferências de tecnologias inovadoras e propriedades intelectuais (RUSSO et al., 2018).

Como exemplo de mecanismos eficientes, tem-se as escolas de inovação tecnológica, voltadas para o público infantil, onde se ensinam conteúdos, como programação, robótica, prototipagem, criação de jogos, e se fazem demais estímulos criativos, para um desenvolvimento intelectual, motor e cognitivo voltado para construção de conhecimento, produções inovadoras e modelos de utilidade. Além da integração das gerações, no cenário social atual (COLLINS; HALVERSON, 2015).

O estabelecimento de sistemas e formatos inovadores, desde o pensamento, e ensino das produções didáticas auxiliares, é de grande valia para o fomento de atividades inovativas cujas instituições, atores e mecanismos, tanto no sistema educacional básico e escolas infantis como nas organizações análogas, com seus laboratórios de pesquisa e desenvolvimento, as agências de fomento, as leis de propriedade intelectual e as universidades, devem atuar de modo que o conhecimento criado possa modificar e difundir as novas tecnologias, e um novo modo organizacional junto à sociedade (RUSSO et al., 2018). 
Muitos professores ainda enxergam o ensino como transmissão de conhecimento por meio de aulas expositivas, mesmo sabendo que existem inovações pedagógicas e materiais tecnológicos, adotando atitudes conservadoras. Sobre isso, Nogueira e Oliveira (2011, p. 10) afirmam:

O conservadorismo não significa que em geral os professores negligenciem a qualidade do ensino, mas que, de certo modo, não tem incentivos para desenvolver a sua capacidade pedagógica e que, muitas vezes, nem dispõe de informação complementar necessária para a solução de problemas concretos, estruturando racionalmente os conhecimentos que vai adquirindo, entrelaçando o que lhe é transmitido com o que ele próprio procura. Sendo assim, o ensino passa a ser mais do que a transmissão de conhecimento. Passa a exigir a utilização de métodos e de ferramentas para o desempenho desse papel ativo. Dessa forma, a atenção principal na ação educativa transfere-se, em grande parte, do ensino para a aprendizagem. Assim, o docente, mais do que transmissor de conhecimento, é um facilitador da aprendizagem.

Sendo o Brasil um país que possui legislação e políticas para promoção da inovação, considera-se pertinente que iniciativas de gestão da inovação e propriedade intelectual transbordem na forma de conhecimento, iniciando-se pela preparação dos profissionais da educação, resultando assim em um ensino diferenciado e de qualidade para os estudantes.

A partir dessa realidade, este estudo tem como objetivo geral confeccionar uma Cartilha de Inovação Tecnológica voltada para profissionais da educação, a fim de sugerir práticas educacionais inovadoras e auxiliar em melhorias no ensino de inovação e tecnologia.

Como objetivos específicos de pesquisa, buscou-se propor a utilização de métodos e práticas inovadoras em sala de aula; conscientizar sobre a importância de significativas mudanças no formato da educação; apresentar ao professor um material que possa ser consultado e que auxilie na formulação de aulas interessantes; estimular no professor o desejo e o gosto pelo estudo de inovações tecnológicas no campo da educação.

\section{Metodologia}

Quanto aos procedimentos técnicos, trata-se de um estudo de revisão bibliográfica, com delineamento metodológico qualitativo, com o propósito de construir e ponderar os métodos e técnicas de pesquisa, tendo como meta a preparação de um material confiável, que possa ser utilizado por outros pesquisadores.

A pesquisa foi realizada em três etapas. A primeira consistiu em um levantamento bibliográfico, que consistiu em buscar estudos sobre ferramentas tecnológicas na escola e o uso da inovação tecnológica e propriedade intelectual em sala de aula. A segunda fase foi a análise dos dados coletados, ou seja, entre os artigos e os estudos selecionados previamente, os dados foram organizados e planilhados a fim de serem utilizados para confecção da cartilha. A terceira fase envolveu a confecção da cartilha de fato: diagramação, estruturação textual, formatação. A estruturação do texto e do layout foi feita com base nos estudos sobre tecnologias educativas realizado por Sabino (2016). As imagens e ilustrações usadas na capa e dentro da cartilha foram feitas por um designer a partir do programa Corel Draw. 
Com a finalidade de adequar o material produzido com as necessidades da população-alvo da pesquisa, o conhecimento prévio e a opinião dos professores sobre os temas que deveriam fazer parte da cartilha foram investigados a partir da demanda preexistente quanto à educação no Brasil, orientada pela literatura pesquisada. Tal levantamento apontou que necessidades específicas do contexto social de cada educador e como adequar a tecnologia e a inovação nesses ambientes é uma dúvida recorrente e um desafio para os professores. Nesse sentido, a cartilha buscou mencionar ferramentas práticas e fáceis que o professor pode adaptar de acordo com o público da sala de aula e com a disponibilidade da escola e/ou do ambiente onde atua.

Logo, o material educativo foi construído pensando nas necessidades de professores em qualquer nível de ensino, uma vez que as tecnologias educacionais e inovações do ensino já fazem parte do ambiente educacional, independentemente de qual seja. As informações da cartilha foram direcionadas para que o professor, como profissional da educação, pudesse conhecer e entender o uso da inovação e da tecnologia em sala de aula, assim como as ferramentas e materiais que possam vir a facilitar e a mediar o ensino no cotidiano. A Figura 1 mostra as etapas da construção da cartilha.

Figura 1 - Etapas metodológicas para a construção da cartilha

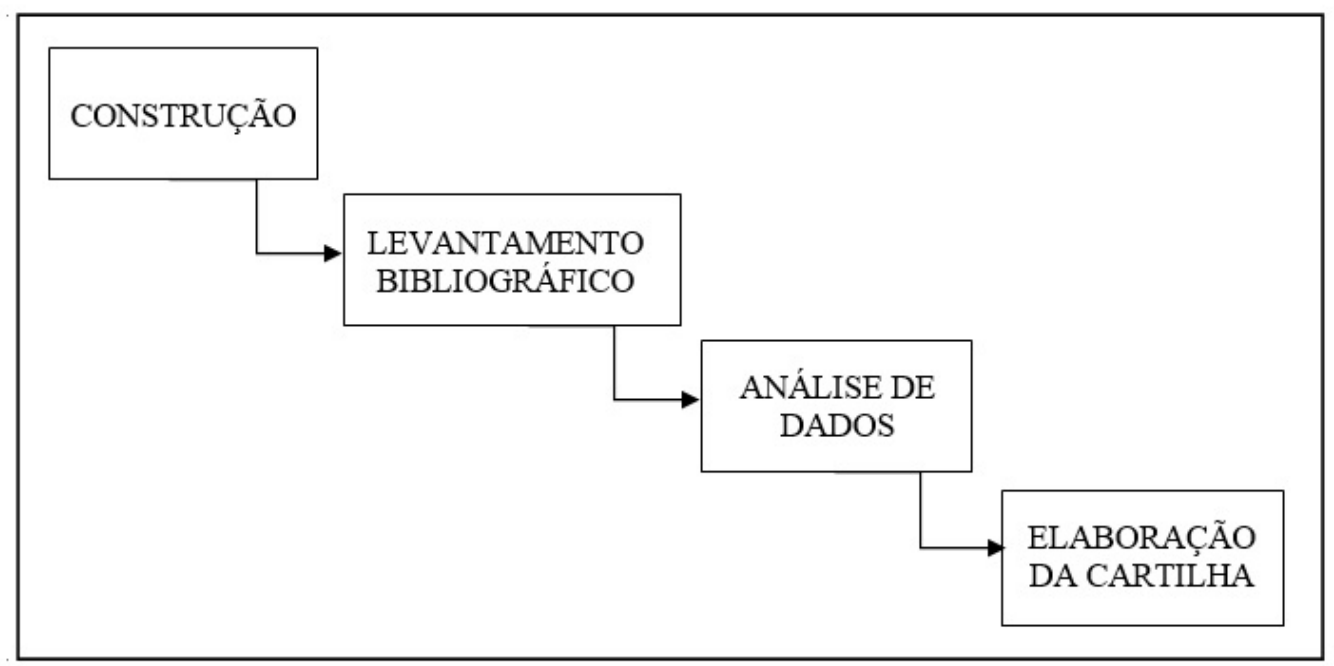

Fonte: Elaborada pelas autoras deste artigo (2020)

No momento da realização de uma pesquisa bibliográfica, a fim de buscar estudos que mencionassem o uso da tecnologia na educação e possibilitassem analisar o conhecimento científico já existente, foram levantados e analisados dados. A busca bibliográfica priorizou materiais que continham modelos de ações para contribuir com metodologias inovadoras de ensino. Em busca nas bases de dados nesse sentido, foram utilizadas as seguintes palavras: educação, inovação. No Quadro 1 estão os estudos encontrados e que contribuíram para a pesquisa. 
Quadro 1 - Compilado de buscas e de resultados na pesquisa das palavras educação e inovação, de diferentes formas

USPTO - Para Inovattion OR Education foram 12,5537 resultados, e para Innovation AND Education foram $\mathbf{2 . 8 6 6}$ resultados, buscando em todos os campos.

SCIENCE DIRECT - Na busca nacional, foram encontrados $\mathbf{5 , 7 3 4}$ resultados com a palavra "Educação", $\mathbf{3 , 2 2 1}$ com a palavra "Inovação", e $\mathbf{4 5 4}$ resultados com ambas as palavras utilizando o operador boleano AND. Na busca internacional, os resultados foram, foram $\mathbf{5 4 7 , 6 6 3}$ com a palavra "Innovation",

$\mathbf{1 , 5 6 6 , 0 0 5}$ com a palavra "Education", e 155,035 com ambas as palavras e o mesmo operador;

SCIELO - Foram encontrados 35.794 resultados para a palavra chave" educação", $\mathbf{3}$, 282 resultados para palavra chave "inovação" e 497 resultados para ambas as palavras, no portal Scielo internacional, no portal Scielo Brasil, os resultados foram 26,716 para palavra "educação", 2,129 para palavra "inovação" e 296 resultados para ambas.

Artigos selecionados e lidos para embasamento - realizado após finalização com base nas referências

Fonte: Elaborado pelas autoras deste artigo (2020)

No momento da confecção da cartilha, o intuito foi elaborar um material para conduzir e auxiliar profissionais da educação na compreensão do ensino da inovação tecnológica, proporcionando a possibilidade de construir materiais educativos com base em evidências e que atingissem um público amplo. Para essa etapa, foram adaptados os conteúdos, a linguagem, a fotografia, o layout e design, conforme o mais adequado visualmente, para se tornar de fácil e rápida compreensão. Detalhes são apresentados no Quadro 2.

Quadro 2 - Linguagem, fotos e desenhos, layout e design para elaboração de materiais educativos impressos

\begin{tabular}{|c|c|c|}
\hline LiNGUAGEM & Fotos E DESENHOS & LAYOUT E DESIGN \\
\hline Descrições de tópicos & Imagens e fotos descritivas & $\begin{array}{c}\text { Fontes e cores para destaque } \\
\text { onde for necessário }\end{array}$ \\
\hline Linguagem compreensível & $\begin{array}{c}\text { Exemplificação por meio de } \\
\text { fotos de atividades verdadeiras }\end{array}$ & $\begin{array}{c}\text { Colorido para chamar atenção } \\
\text { aos tópicos principais. }\end{array}$ \\
\hline Descrição dinâmica & Imagens de boa qualidade & $\begin{array}{c}\text { Destaque para títulos por meio negritos, } \\
\text { itálico, sublinhado, e cores diferenciadas. }\end{array}$ \\
\hline $\begin{array}{c}\text { Conceitos abstratos } \\
\text { demonstrados com exemplos }\end{array}$ & $\begin{array}{c}\text { Fotos e imagens dispostas } \\
\text { de forma adequada }\end{array}$ & $\begin{array}{c}\text { Adequada disposição de textos e imagens } \\
\text { para facilitar e agradar a leitura }\end{array}$ \\
\hline $\begin{array}{c}\text { Destaque para } \\
\text { sentenças principais }\end{array}$ & $\begin{array}{c}\text { Informações enfatizadas com } \\
\text { o uso de fotos e desenhos }\end{array}$ & Correta proporção na disposição dos itens \\
\hline
\end{tabular}

Fonte: Elaborado pelas autoras deste artigo (2020)

A partir do diagnóstico situacional e do levantamento bibliográfico, produziu-se a cartilha sobre diretrizes e bases e aplicabilidade de metodologias inovadoras na educação e processos de aprendizagem, com ilustrações, layout, design e escrita acessível e objetiva para facilitar a compreensão do conteúdo abordado. 


\section{Resultados e Discussão}

A cartilha foi composta de 37 páginas com capa, contracapa, ficha técnica, sumário e folha de apresentação. Antes de iniciar os tópicos específicos com exemplificação das metodologias inovadoras que podem ser aplicadas em sala de aula e com o estudo de caso de uma escola que já utiliza a tecnologia e inovação (caso de sucesso), o primeiro capítulo da cartilha mencionou as metodologias inovadoras na educação de forma geral: processos de aprendizagem e suas etapas; alunos do centro da aprendizagem.

Posteriormente, o conteúdo da cartilha apresentou o estudo de caso da escola de inovação tecnológica Protobot, exemplificando a aplicabilidade da tecnologia e inovação na educação a partir de uma metodologia ativa com foco na aprendizagem em equipes e na aprendizagem em projetos. Nesse capítulo, a cartilha traz a partir de texto e fotos o que é a metodologia ativa, como funciona a aprendizagem em equipes ou pares e o que é a aprendizagem baseada em projetos. Ainda sobre o estudo de caso, a cartilha coloca as Diretrizes e Bases da metodologia ativa utilizada na escola em questão: criatividade, colaboração, resolução de problemas, tecnologia, inovação, prototipagem.

Dando sequência, a cartilha trouxe um tópico sobre as competências desenvolvidas. Esse item mencionou alguns pontos a serem observados em uma metodologia ativa, como enfoque na preparação e desenvolvimento de habilidades do profissional do futuro. Dez habilidades que o profissional da educação precisa expor e buscar aflorar no estudante: capacidade de reestruturação do conhecimento; habilidade em mediação de situações e pessoas; disposição para orientar; capacidade de discernimento e decisões; habilidade intelecto afetiva; coordenação em equipe; gestão pessoal e coletiva; capacidade imaginativa e de criação; capacidade de ponderamento e equilíbrio; capacidade de identificar e solucionar adversidades.

No último item, intitulado "Sugestão de atividade: exemplificando a metodologia", foram colocados dois planos de aula utilizando lego. O primeiro plano de aula teve por objetivo usar um sensor de movimento (Sensor de movimento do Milo) para detectar a presença de uma amostra, no caso, uma planta. O segundo plano de aula foi sobre o semáforo, com o objetivo de desenvolver um simulador de sistema de semáforos. Ambos os planos utilizaram habilidades como: planejamento, preparação, apresentação. Ao final de cada projeto, os alunos precisaram responder algumas questões sobre suas expectativas e o que realmente aconteceu. E também questões específicas sobre cada projeto, por exemplo, saber como uma sonda espacial se comporta em outro planeta (Plano de aula 1). Ao final, a cartilha coloca as referências bibliográficas usadas.

Buscando utilizar uma linguagem simples e envolvente, optou-se por usar frases mais simples e menos elaboradas e/ou técnicas. A fim de chamar a atenção das partes importante, os títulos e subtítulos se diferenciaram do restante do texto, inseridos com imagens em azul ao fundo. Todos os subitens e explicações em cada capítulo continham fotos dos alunos praticando. No caso dos planos de aula, o passo a passo de cada experimento tecnológico também foi demonstrado em esquemas $e$ fotos. A fonte da letra utilizada para confecção da cartilha foi razoavelmente grande, facilitando a leitura. Além disso, a didática prevaleceu na organização do conteúdo e tudo foi explicitamente mensurado e mencionado; todos os processos.

Um ponto positivo da cartilha é que ela mencionou a inovação e tecnologia aplicada à educação de maneira simples, de forma que os profissionais da educação de qualquer nível/ 
etapa de ensino podem ter acesso aos processos e adaptá-los de acordo com seus alunos. Entretanto, a exclusividade dos planos de aula ser direcionado para crianças e pré-adolescentes apresenta-se como uma limitação deste estudo. Outra limitação foi o estudo de caso descrever apenas uma escola e não ter dados de outras instituições de ensino para fazer um comparativo ou trazer outras inovações usadas em sala de aula, além de protótipos usando peças de lego. A Figura 2 apresenta algumas páginas da cartilha.

Figura 2 - Algumas páginas da Cartilha de Inovação Tecnológica para profissionais da educação
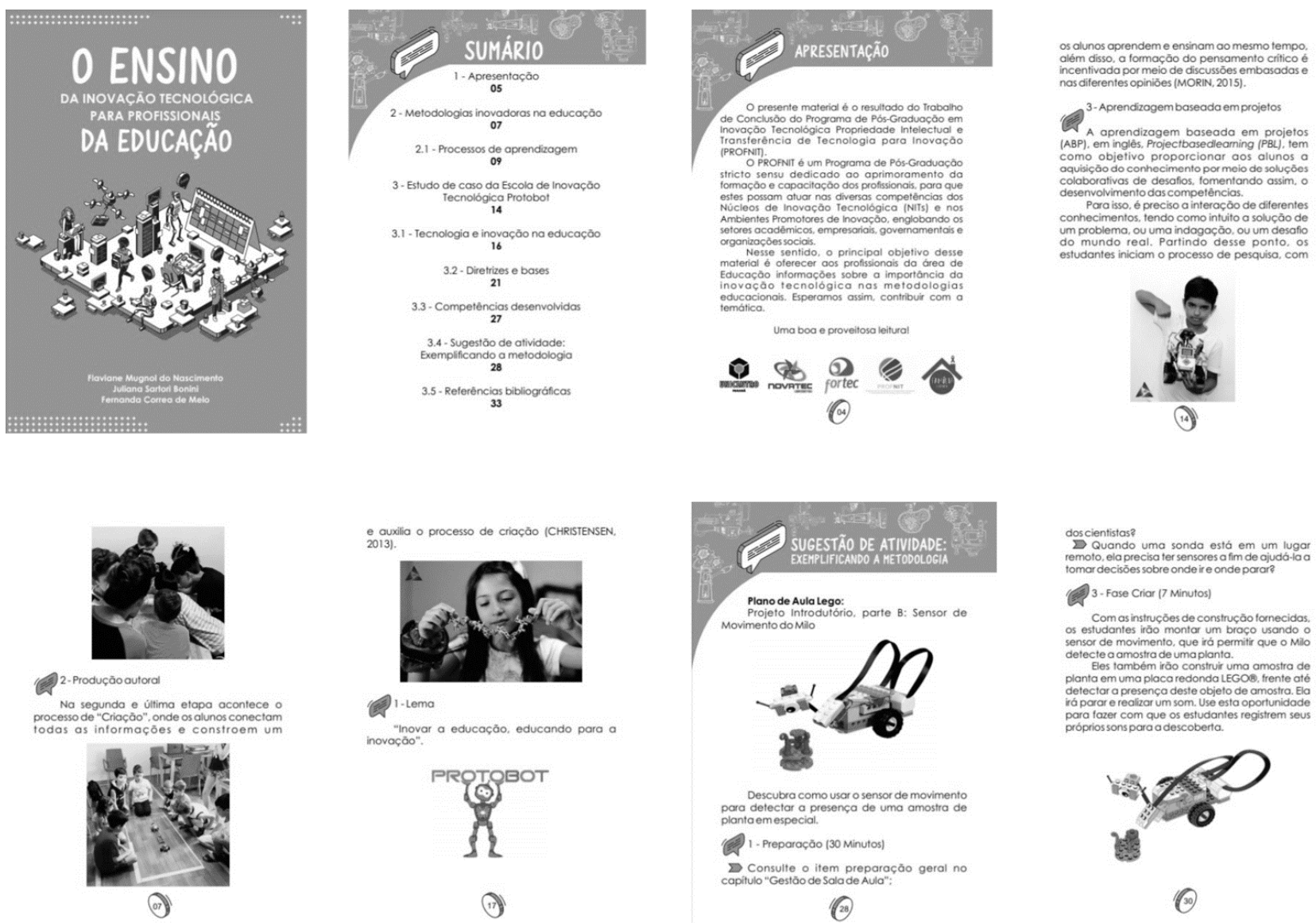

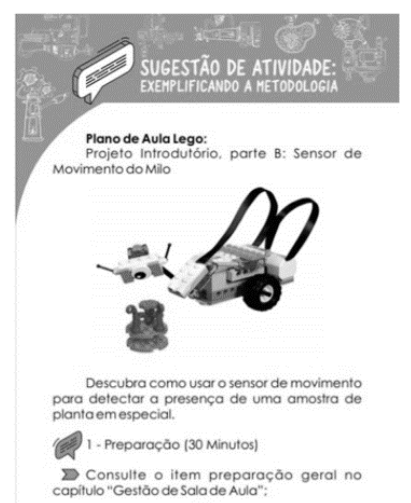

(20)

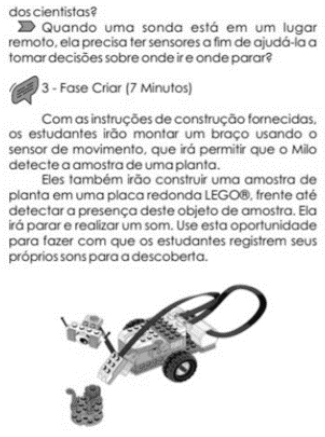

(6)

Fonte: Elaborada pelas autoras deste artigo (2020)

Quanto à distribuição da cartilha, a mesma foi disponibilizada para download gratuito no site Amazon, por meio da plataforma E-book Kindle e pode ser acessada no endereço https:// www.amazon.com.br/ensino-Inovação-Tecnologica-profissionais-educacao-ebook (Figura 3). A próxima etapa da pesquisa será distribuir esse endereço eletrônico entre os profissionais da educação para que leiam e deem seu retorno acerca do material, conteúdo etc., realizando suas considerações. O objetivo de disponibilizá-la em meio eletrônico foi torná-la acessível, a fim de que cumpra seu papel, visto que foi confeccionada a partir das necessidades desses profissionais. 
Figura 3 - Cartilha disponibilizada em endereço eletrônico

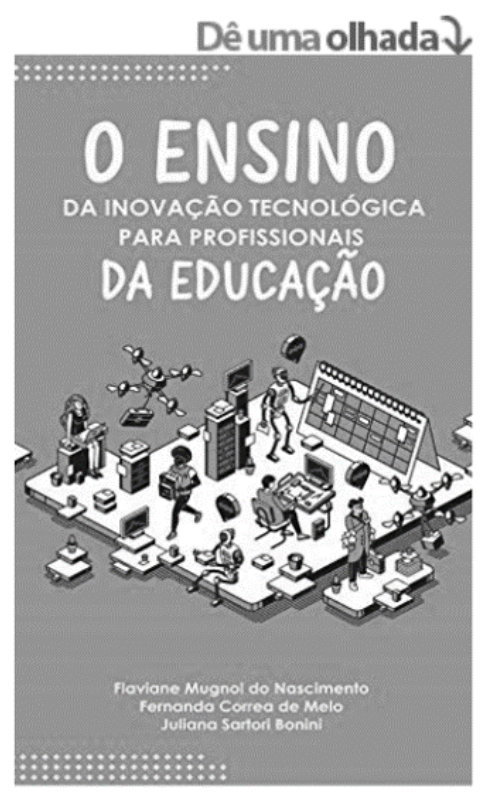

\section{O ensino da Inovação Tecnológica para profissionais da educação eBook Kindle}

por Flaviane Mugnol do Nascimento (Autor), \& 2 mais Kindle

Ver todos os formatos e edições

Kindle

Leia com nossos apps gratuitos

O presente material é o resultado do Trabalho de Conclusão do Programa de Pós-Graduação em Inovação Tecnológica Propriedade Intelectual e Transferência de Tecnologia para Inovação (PROFNIT). O PROFNIT é um Programa de Pós-Graduação stricto sensu dedicado ao aprimoramento da formação e capacitação dos profissionais, para que estes possam atuar nas < Leia mais

Fonte: Elaborada pelas autoras deste artigo (2020)

Com sua confecção, foi observado que o ensino da tecnologia com ênfase em metodologias inovadoras é bastante relevante, pois, entre os diversos conceitos de ensino inovador, o conceito de uso de tecnologias ocupa uma posição importante e complexa. Na produção da cartilha, buscou-se realizar um trabalho dinâmico, criativo e envolvente, transparecendo isso em suas páginas, com a intenção de levar os leitores a utilizarem efetivamente a cartilha como tendência metodológica norteadora para seus trabalhos.

Quanto à validação da cartilha, ela ainda será realizada pelos profissionais da educação em um segundo momento. Apesar disso, alguns itens foram considerados na sua elaboração. Como essa cartilha é resultado de uma dissertação do Programa de Pós-Graduação em Propriedade Intelectual e Transferência de Tecnologia para Inovação (PROFNIT), da Universidade Estadual do Centro-Oeste, alguns professores do programa sugeriram pontos a se considerar na construção da cartilha, que, posteriormente, serão utilizados na validação, a partir de uma análise quantitativa. As informações estão contidas no Quadro 3.

Os itens listados para conferência ao elaborar a cartilha foram separados em seis categorias, a saber: conteúdo, linguagem, ilustrações, layout, motivação e cultura. Cada categoria teve seus subitens a serem avaliados. $\mathrm{O}$ uso de itens, a conferência do checklist e a preocupação com o conteúdo são provenientes do fato de que, em estudos com cartilhas e desenvolvimento de tecnologias educativas, é importante investigar se o conteúdo se aplica ao contexto que será utilizado, pois, mesmo que o conteúdo seja compreensível e válido, é preciso que a tecnologia seja aplicável, tornando o uso da cartilha viável. Nesse sentido, a viabilidade de uma cartilha educativa e/ou tecnológica ultrapassa a compreensão do leitor e é validada pela sua colocação no campo de atuação, por meio dos sujeitos. 
Quadro 3 - Itens considerados para construção da cartilha

\begin{tabular}{|c|c|}
\hline Item & Subitem \\
\hline \multirow{7}{*}{ 1. Conteúdo } & 1.1) O conteúdo atende uma possível situação de atuação do professor. \\
\hline & 1.2) Títulos e subtítulos divididos de forma coerente. \\
\hline & 1.3) Trechos em destaque merecem ser destacados. \\
\hline & 1.4) Conteúdo atende às necessidades do público-alvo. \\
\hline & 1.5) Existe lógica na sequência do texto. \\
\hline & 1.6) O conteúdo é relevante para ser informado aos professores. \\
\hline & 1.7) O conteúdo está correto do ponto de vista científico. \\
\hline \multirow{3}{*}{ 2. Linguagem } & 2.1) A redação é compatível com o público-alvo. \\
\hline & 2.2) As frases são atrativas e não cansativas. \\
\hline & 2.3) Existe clareza e objetividade no texto. \\
\hline \multirow{4}{*}{ 3. Ilustrações/Imagens } & 3.1) As imagens condizem com o conteúdo. \\
\hline & 3.2) As ilustrações são compreensíveis. \\
\hline & 3.3) As legendas ajudam o leitor a compreender a imagem. \\
\hline & 3.4) O número de imagens é suficiente para abordar o conteúdo. \\
\hline \multirow{3}{*}{ 4. Layout } & 4.1) A fonte e o tamanho da letra favorecem a leitura. \\
\hline & 4.2) As cores utilizadas no texto viabilizam a leitura. \\
\hline & 4.3) O número de imagens é suficiente para abordar o conteúdo. \\
\hline \multirow{2}{*}{ 5. Motivação } & 5.1) O leitor é incentivado a prosseguir a leitura pelo conteúdo. \\
\hline & 5.2) A cartilha é esclarecedora. \\
\hline 6. Cultura & 6.1) A cartilha atende aos vários perfis de professores. \\
\hline
\end{tabular}

Fonte: Adaptado de Galindo Neto et al. (2017)

Considerar tais itens na confecção da cartilha faz com que ela contribua de fato para tornar a informação clara e atraente para o leitor. Cartilhas direcionadas para o campo da educação, quando bem escritas e ilustradas, são ferramentas relevantes para serem utilizadas nos mais diversos contextos e com alunos de todas as séries, uma vez que pode ser adaptada.

A literatura menciona que a necessidade de materiais de apoio, como cartilhas, que mencionem a inovação e a tecnologia, é iminente, pois o mundo mudou e hoje se consome e se produz muito mais por meias tecnologias que outrora. Logo, na educação, que é a base da construção social, não poderia ser diferente (SILVA, 2011).

Na construção do material, foram utilizadas referências da área da educação e da tecnologia. Imagens foram um recurso de exemplificação e de melhora na visualidade da cartilha. Nos textos se destacam principalmente aspectos do processo de ensino e de aprendizagem que procuram envolver com a estratégia escolhida, levando em conta a capacidade do leitor, o público-alvo, a possibilidade de observar, de interpretar, de analisar e de pensar cientificamente identificando novas possibilidades de refletir sobre o que está sendo mostrado por meio do material. Sua formulação é simples e de baixo custo e busca motivar para o interesse, a interação e a compreensão na área. 
Segundo as ideias de Aquino e Santos (2011), ao propor tais estratégias de ensino, busca-se uma revisão de diversos conceitos por parte dos profissionais da educação, oportunizando o desenvolvimento de um modo inovador de ensinar. Também coloca o profissional em uma situação prática e coletiva de planejamento didático-pedagógico (AQUINO; SANTOS, 2011).

A estratégia da produção e de apresentação desse modelo didático visa a possibilitar instrumentalizar o futuro dos profissionais da educação, uma vez que, a partir da análise dos materiais já existentes, foi possível perceber a necessidade da argumentação em torno dos eixos propostos para o desenvolvimento da cartilha. Além disso, ao propor a elaboração do material, foram proporcionados momentos de fundamentação teórica para a prática do ensino, uma vez que há uma necessidade, como a exposta, de buscar pela relação entre a teoria da área e a vivência no planejamento pedagógico (BITTENCOURT, 2018).

O uso de materiais didáticos diversificados, por profissionais da educação, permite dinamizar suas produções e estudos, além de constituir novas relações entre o conteúdo e a construção de conhecimento. Sabe-se que produção de materiais didáticos para agentes da educação não só é viável, como também pode atingir bons resultados nos processos de ensino- aprendizagem. Com este trabalho estabelecemos algumas bases para este tipo de produções, principalmente no que tange a educação (AQUINO; SANTOS, 2011).

Logo, é nítida a utilidade e benefícios, de uma cartilha, como a proposta neste trabalho. Isso porque é inerente, já que, quando um profissional utiliza diferentes tipos de recursos didáticos, ele não só passa seu modo de transmissão de conhecimento, como o torna mais interessante, diminuindo a possível monotonia à qual o ensino tradicional possa estar associado, como também pode levar aluno e o professor a melhores resultados (JUSTINO, 2011).

De acordo com as ideias de Souza (2017), vale observar que a construção do conhecimento é um trabalho ilustre destinado àqueles que se dedicam à educação. No entanto, nem sempre há exatidão nessa nobre tarefa, o que a torna bastante complexa e, muitas vezes, intensa, de modo que a utilização de recursos didáticos de qualidade, que promovam um melhor desempenho, é sempre relevante. Ainda, nesse sentido, é válido observar que recursos didáticos são materiais amplamente utilizados para auxiliar o ensino e a aprendizagem em relação ao conteúdo proposto. Por isso, devem servir como uma espécie de motivação, inclinando a um interesse mais amplo pelo conteúdo e facilitando a compreensão dele (SOUZA, 2017).

Para reafirmar tais conceitos, no que diz respeito à utilização de recursos didáticos, faz-se necessário perceber que eles podem ser desenvolvidos a partir de elementos simples, por exemplo, imagens, cores e designs interessantes. Isso faz com que se torne mais interessante o aprendizado (LARROSA, 2017).

Os materiais didáticos são de fundamental importância no processo de desenvolvimento cognitivo de quem os utiliza e devem ter o poder de aproximar o interlocutor do conteúdo, facilitando, assim, sua concreta absorção. No contexto diário dos sistemas de aprendizagem $e$ ensino, diversos recursos didáticos podem vir a ser usados. A escolha depende de fatores como a visão do utilizador do recurso, a finalidade de sua utilização, a aceitação do público-alvo, entre outros. E, ainda que as opções de utilização sejam diversas, o critério de escolha deve ser selecionado depois de várias considerações (JUSTINO, 2011). 
Um dos pontos que devem ser analisados para essa escolha é que a utilização do material deve ocupar as lacunas que o ensino tradicional e comum tem, tendo a capacidade de proporcionar a ampliação da capacidade de construção do conhecimento, além de servir como estímulo ao ensino (JUSTINO, 2011).

\section{Considerações Finais}

A construção da cartilha acerca de inovação tecnológica para profissionais da educação considerou o conhecimento do público-alvo encontrado na literatura, a partir de estudos já publicados. A validação do conteúdo que constituiu a cartilha foi realizada a partir da sugestão de professores do Programa de Pós-Graduação em Propriedade Intelectual e Transferência de Tecnologia para Inovação (PROFNIT), da Universidade Estadual do Centro-Oeste e considerou alguns itens e subitens específicos. Para que os professores tivessem acesso à cartilha, ela foi disponibilizada como e-book em um endereço eletrônico para download gratuito. Em uma pesquisa futura, pretende-se realizar a validação da cartilha a partir da opinião daqueles que a utilizarão em sala de aula, ou seja, o público a quem se destina tal material.

Os critérios adotados, as etapas que foram seguidas na confecção e o referencial teórico pesquisado para construir a cartilha vão de acordo com a perspectiva de se obter um material educativo no âmbito da tecnologia e inovação, passível de ser utilizado por professores de todos os níveis educacionais. Essa característica pode contribuir com a tomada de decisão dos professores envolvidos no processo de construção de saberes e diversificação de estratégias de ensino, independentemente da temática.

A versão final da cartilha pode ser acessada por profissionais da educação e pelos demais sujeitos da comunidade escolar que tenham interesse em conhecer o conteúdo e entender como um ambiente de ensino que prioriza a inovação e a tecnologia pode enriquecer as práticas pedagógicas e a aprendizagem.

Por fim, é necessário que esta cartilha seja viabilizada entre os profissionais da educação, com a realização de estudos mais profundos da sua aplicação no sistema de ensino, com o intuito de investigar quão efetivo o material pode ser como recurso didático e tecnológico, produzindo conhecimentos e os aplicando na prática da sala de aula.

\section{Perspectivas Futuras}

A cartilha que este trabalho menciona foi o primeiro ponto para inserir a inovação tecnológica para profissionais da educação, com a demonstração do passo a passo e da qualidade final do material. Muitas melhorias podem ser feitas, sobretudo na perspectiva de tornar a produção de material de apoio no âmbito da inovação um processo contínuo e uma preocupação de todos.

Em relação à cartilha, esta foi elaborada para mencionar o uso da tecnologia na educação. Futuramente pode ser realizado um estudo com a finalidade de construir e de inserir conhecimentos tecnológicos e de inovação em outros meios de acesso, por exemplo, um aplicativo que possa ser facilmente acessado pelos professores na tela do celular. 
Diante disso, a principal ação a se tomar e a proposta futura deste estudo devem considerar validar o conteúdo da cartilha com profissionais da educação atuantes em diferentes níveis de ensino, a fim de que possam contribuir para as melhorias e que opinem sobre a inserção de tal cartilha no cotidiano escolar. Essa validação possibilitará entender se os pontos discutidos foram relevantes.

Entende-se que, além da validação, também poderia ser interessante ter dados para comparar acerca do uso de inovações tecnológicas no ambiente escolar. Sendo assim, esta pesquisa é um ponto inicial para uma realidade muito maior: a tecnologia e a educação efetivamente unidas para transformar a realidade escolar desde o princípio.

\section{Referências}

AQUINO, J. B.; SANTOS, M. C. Maquetes: conceitos e práticas na elaboração de produtos didáticos. Espaço e Movimento, [s.l.], v. 1, n. 7, p. 61-67, 2011.

ASSUMPÇÃO, F. C. et al. Estruturação e Planejamento de Núcleos de Inovação Tecnológica. Florianópolis: Pronit, 2010.

BERGMANN, J.; SAMS, A. Flip Your Classroom: Reach Every Student in Every Class Every Day. Washington, DC: International Society for Technology in Education, 2012.

BITTENCOURT, C. M. F. Ensino de história: fundamentos e métodos. São Paulo: Cortez, 2018.

COLLINS, A.; HALVERSON, R. The second educational revolution: Rethinking education in the age of technology. Journal of Computer Assisted Learning, [s.l.], v. 26, n. 1, p.18-27, 2015.

GALINDO NETO, N. M. et al. Primeiros socorros na escola: construção e validação de cartilha educativa para professores. Acta Paulista de Enfermagem, [s.l.], v. 30, n. 1, p. 87-93, 2017.

IMBERNÓN, F. Formação continuada de professores. Porto Alegre: Artmed, 2010.

ISTOÉ. Brasil cai para última posição em educação em ranking global. 2020. Disponível em: https://www.istoedinheiro.com.br/xbrasil-cai-para-ultima-posicao-em-educacao-em-ranking-globalde-competitividade/. Acesso em: 31 maio 2021.

JUSTINO, M. N. Pesquisa e recursos didáticos na formação e prática docente. Curitiba: Ibpex, 2011.

KENSKI, V. M. Educação e tecnologias: um novo ritmo da informação. 8. ed. Campinas: Papirus, 2012.

LARROSA, J. B. A experiência e suas linguagens. In: LARROSA, J. B. Tremores: escritos sobre experiência. Belo Horizonte: Autêntica, 2017. p. 35-56.

LIBÂNEO, J. C. Pedagogia e pedagogos, para quêe? 1. ed. São Paulo: Cortez, 2018.

NOGUEIRA, R. S.; OLIVEIRA, E. B. A importância da Didática no Ensino Superior. 2011.

Disponível em: http://www.ice.edu.br/TNX/storage/webdisco/2011/11/10/outros/75a110bfebd8a8895

4e5f511ca9bdf8c.pdf. Acesso em: 12 nov. 2021.

RUSSO, S. L. et al. Propriedade intelectual, tecnologias e inovação. Aracaju: Capacite, 2018. 399 p. 
SABINO, L. M. M. Cartilha educativa: elaboração e validação. 2016. 171f. Dissertação (Mestrado em Enfermagem) - Universidade Federal do Ceará, Fortaleza, 2016.

SILVA, M. Sala de aula interativa: a educação presencial e a distância em sintonia com a era digital $e$ com a cidadania. In: CONGRESSO BRASILEIRO DA COMUNICAÇÃO, 24., 2011. Anais do XXIV Congresso Brasileiro da Comunicação. Campo Grande: CBC, 2011.

SOUZA, S. E. O uso de recursos didáticos no ensino escolar. Arquivos do Mudi, [s.l.], v. 11, n. 2, p. 10-14, 2017.

VASCONCELLOS, C. S. Formação didática do educador contemporâneo: desafios e perspectivas. São Paulo: Cultura Acadêmica, 2011.

\section{Sobre as Autoras}

\section{Flaviane Mugnol do Nascimento}

E-mail: flaviamugnol@gmail.com ORCID: https://orcid.org/0000-0002-6583-0801

Mestre pelo Programa de Pós-Graduação em Propriedade Intelectual e Transferência de Tecnologia (UNICENTRO). Endereço profissional: Escola de Inovação Tecnológica Protobot, Rua Dezessete de Julho, n. 1.013, Trianon, Guarapuava, PR. CEP: 85012-040.

\section{Fernanda Correa de Melo}

E-mail: fernandacorreademelo@gmail.com ORCID: http://orcid.org/0000-0002-4091-4486

Mestre pelo Programa de Pós-Graduação em Propriedade Intelectual e Transferência de Tecnologia (UNICENTRO). Endereço profissional: Associação de Estudos, Pesquisa e Assistência às Pessoas com Doença de Alzheimer, Rua Edson Nobre de Lacerda, n. 260 e 265, Alto da XV, Guarapuava, PR. CEP: 85070-330.

\section{Juliana Sartori Bonini}

E-mail: juliana.bonini@gmail.com

ORCID: https://orcid.org/0000-0001-5144-2253

Pós-doutora em Medicina (PUCRS/RS).

Endereço profissional: Professora Adjunta do Departamento de Farmácia, da Universidade Estadual do CentroOeste (UNICENTRO), Rua Salvatore Renna, n. 875, Santa Cruz, Guarapuava, PR. CEP: 85015-430.

\section{Deise Mara Soares}

E-mail: deisemarasoares98@gmail.com

ORCID: https://orcid.org/0000-0002-7425-6880

Especialista em Direito do Trabalho e Direito Processual do Trabalho (Escola Superior Verbo Jurídico, VJ, Brasil). Endereço profissional: Instituto Nacional do Seguro Social, Agência da Previdência Social em Santa Maria, Rua Venâncio Aires, n. 2.114, Centro, Santa Maria, RS. CEP: 97015-001. 